\title{
LAS OBRAS DE LAS EXPRESIONES CULTURALES TRADICIONALES EN MÉXICO: MARCO NORMATIVO INTERNACIONAL Y NACIONAL
}

\author{
AMPARO ALICIA OVIEDO ARBELÁEZ* \\ LAURA SOFÍA GÓMEZ MADRIGAL**
}

\section{INTRODUCCIÓN}

Unos de los temas más controvertidos en las últimas décadas a nivel internacional y nacional en materia de propiedad intelectual es el de la protección de los recursos genéticos, los conocimientos tradicionales y el folclore. El debate se fue gestando en diferentes foros y organismos internacionales hasta encontrar su nicho de diálogo y negociación en el Comité Intergubernamental sobre Recursos Genéticos, Conocimientos Tradicionales y Folclore de la Organización Mundial de la Propiedad Intelectual, OMPI, en el año 2000, gracias a la iniciativa colombiana.

* Investigadora miembro asociada del Centro de Estudios y de Investigación en Derechos Inmateriales de la Universidad de Paris Sud, Cerdi-Paris, Francia. Consultora en Propiedad Intelectual y jefa de tutores de enseñanza a distancia de la Academia Mundial de la Organización Mundial de la Propiedad Intelectual (OMPI) desde el año 2000. Candidata a doctora en Derecho de la Universidad de Lille II, Francia, con maestría en Derecho de la misma Universidad. Abogada de la Pontificia Universidad Javeriana de Colombia. Contacto: amaparo.oviedo@u-psud.fr

** Doctora en Derecho egresada del Doctorado Interinstitucional en Derecho de ANuies, con investigación en el tema de la protección de los conocimientos tradicionales. Profesora de la Facultad de Derecho de la Universidad de Colima, México. Actualmente es investigadora invitada en el Centre d'études en Sciences sociales sur les mondes africains, américains et asiatiques (cessma) de la Universidad Paris Diderot, Francia. Ha cursado diversas especialidades en el área de Propiedad Intelectual. Es profesora desde 2004 de diferentes cursos impartidos por la ompr. Contacto: sgomez@ucol.mx

Fecha de recepción: 14 de enero de 2015. Fecha de aceptación: 12 de febrero de 2015. Para citar el artículo: Oviedo Arbeláez, A. A. y Gómez Madrigal, L. S. Las obras de las expresiones culturales tradicionales en México: marco normativo internacional y nacional. Revista La Propiedad Inmaterial n. ${ }^{\circ} 19$, Universidad Externado de Colombia, enero-junio, 2015, pp. 5-29. DOI: 10.18601/16571959.n19.01 
En la base de ya más de 14 años de diálogo en la OMPI ha estado el aumento vertiginoso de la llamada biopiratería, así como la explotación comercial del saber tradicional de los pueblos indígenas y de las expresiones de las culturas tradicionales de los países a través de los medios masivos de información y de las nuevas tecnologías.

Dos esferas de negociación se han venido retroalimentando: la esfera nacional y la esfera internacional. Por un lado, han sido grandes impulsores de acuerdos internacionales los países que han legislado a nivel interno sobre la materia y que urgen a un acuerdo internacional en virtud del número importante de Estados que no protegen las creaciones de las expresiones culturales tradicionales por considerarlas de dominio público. Por otra parte, las negociaciones en la ompi han servido para crear nuevos espacios de diálogo y concertación a nivel nacional, que en algunos casos han urgido a una regulación más exhaustiva a nivel interno.

En ambas esferas de debate, el nudo gordiano de las discusiones ha estado centrado no solo en definir la naturaleza jurídica de la protección de los conocimientos y las expresiones culturales tradicionales, sino en su identificación, conservación y utilización. La complejidad del tema radica en los aspectos sociológicos, psicológicos, etnológicos, históricos, culturales, económicos y políticos implicados.

Mediante este artículo presentaremos el estado actual del marco normativo internacional y nacional vigente para la protección de las obras de las expresiones culturales tradicionales en México.

\section{Conceptos fundamentales}

\section{Antecedentes}

Es incuestionable que México se encuentra compuesto por una sociedad pluricultural sustentada por los pueblos y comunidades indígenas que habitaban el territorio nacional desde antes de la conquista de los españoles; sociedades que han subsistido y que hoy día forman la población indígena más numerosa del continente americano ${ }^{1}$.

Antes de la conquista y la colonización, estos pueblos formaban una sociedad regulada por sus propias normas y costumbres, a las cuales se vino a superponer el nuevo Estado sin tomar en cuenta esos derechos originarios. Después de la independencia e incluso de la Revolución, la situación no cambió. Por el contrario, una vez establecida la paz en el territorio nacional y con la promulgación de la

1. El Censo de Población y Vivienda realizado en 2010 reportó que 15.7 millones de personas se consideran indígenas. Cfr. Comisión Nacional para el Desarrollo de los Pueblos Indígenas. Acciones de Gobierno para el Desarrollo Integral de los Pueblos Indígenas. Informe de 2011, México, 2012, p. 7. 
Constitución de 1917, las políticas del gobierno mexicano respecto a los pueblos indígenas fueron integracionistas, es decir, orientadas a la construcción de una identidad nacional única. Se dejó de lado la riqueza cultural de dichos pueblos, negándoseles cualquier derecho a una autonomía o a contar con identidad propia, intentando atraerlos hacia un molde mestizo nacional, con las mismas costumbres, tradiciones y formas de vida que lograría la homogeneización entre indios y no indios para lograr una verdadera civilización ${ }^{2}$.

\section{Pueblos y comunidades indígenas}

¿Y qué es el indigenismo? Según Luis Villoro, se define como "el conjunto de percepciones teóricas y de procesos concienciales que, a lo largo de las épocas,

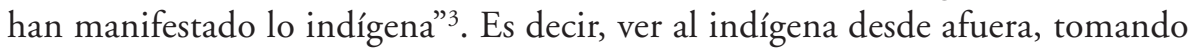
conciencia de que la percepción que se tiene sobre ellos ha cambiado a través del tiempo, pero reconociendo su capacidad para ampliar y consolidar sus instituciones, pues están legitimados para que se les reconozcan jurídicamente sus derechos, largamente denegados.

De acuerdo con las políticas sobre indígenas del Banco Mundial, el término indígenas es usado en un sentido genérico para referirse a un grupo cultural, social, distinto y vulnerable, que posee las siguientes características en distintos grados:

- Una identificación propia como miembros de un grupo cultural indígena y el reconocimiento de esta identidad por otros.

- Unido a un territorio geográfico determinado y a sus recursos naturales.

- Con instituciones culturales, económicas o políticas separadas de las del grupo dominante de la sociedad.

- Un lenguaje indígena, generalmente diferente del idioma oficial del país o región en el que se encuentra ${ }^{4}$.

\section{Expresiones Culturales tradicionales o del folclore}

Estas sociedades han demostrado a lo largo de la historia que cuentan con una gran capacidad de supervivencia, de ahí que hayan logrado preservar gran parte de sus tradiciones, reflejadas a través de sus valores, creencias, costumbres y ob-

2. Castillo Ramírez, Guillermo. Las representaciones de los grupos indígenas y el concepto de nación en Forjando Patria de Manuel Gamio. Cuicuilco, n. ${ }^{\circ}$ 20, enero-abril, 2013, pp. 11-34.

3. Luis Villoro, citado por Orlando Aragón Andrade, Indigenismo, movimientos y derechos indígenas en México. La Reforma del Artículo 4. ${ }^{\circ}$ Constitucional de 1992, México, Universidad Michoacana de San Nicolás de Hidalgo, 2007, p. 38.

4. Cfr. Sobrevila, Claudia, The Role of Indigenous Peoples in Biodiversity Conservation. The Natural but Often Forgotten Partners, trad. propia, Washington, The World Bank, , mayo 2008, p. 3. 
jetos materiales 5 . Sin embargo, la globalización ha modificado radicalmente la capacidad de protección de su cultura, pues los pueblos indígenas se encuentran conectados con el mercado mundial, donde las empresas y corporaciones se interesan en desarrollar nuevos productos basados en sus tradiciones y/o cultura.

Es por ello que México ha adoptado diversas medidas tendientes a proteger este saber ancestral siguiendo la postura internacional marcada por la Organización Mundial de la Propiedad Intelectual al clasificar las distintas categorías de saberes tradicionales en tres rubros: Recursos Genéticos (RR.GG.), Conocimientos Tradicionales (сс.тт.) y Expresiones del Folclore (ЕСт) ${ }^{6}$. No obstante, para efectos de este estudio, se abordarán únicamente las cuestiones jurídicas relativas a la protección de las obras derivadas del folclore, conocidas también como expresiones culturales tradicionales, es decir, las producciones elaboradas con elementos característicos del patrimonio artístico tradicional creado y mantenido por una comunidad o por personas que reflejan las expectativas artísticas tradicionales de dicha comunidad. Se consideran expresiones culturales tradicionales:

- Las expresiones verbales, como cuentos, poesías y acertijos populares, las palabras, los signos, los símbolos y las indicaciones.

- Las expresiones musicales, como las canciones populares y la música instrumental.

- Las expresiones corporales, como danzas populares, representaciones escénicas y formas artísticas o rituales, con independencia de que estén o no fijadas en un soporte material.

- Las expresiones tangibles, tales como las artesanías, los instrumentos musicales, las esculturas, las joyas, los textiles o las indumentarias ${ }^{7}$.

Los términos "expresiones culturales tradicionales" (ЕСT) y "expresiones del folclore" se utilizan de manera indistinta para definir las manifestaciones derivadas de los procesos creativos que reflejan la identidad cultural, social y los valores de una comunidad ${ }^{8}$. Es la parte viva que de manera material e inmaterial transmite el sentir de la sociedad que lo recrea día tras día.

5. Cfr. Macionis, John y Plummer, Ken, Sociología, España, Pearson, 2007, p. 108.

6. Cfr. Gómez, Laura Sofía. Protección de la tradición. Los derechos no tradicionales de la propiedad intelectual. La Propiedad Inmaterial, núm. 17, Universidad Externado de Colombia, 2013, p. 107. Cfr.: http://revistas.uexternado.edu.co/index.php?journal=propi n\&page $=$ article\&op $=$ view $\&$ path $\% 5 B \% 5 D=3581$

7. Cfr. Organización Mundial de la Propiedad Intelectual, Propiedad Intelectual y Conocimientos Tradicionales, Folleto n. ${ }^{\circ}$ 2, Publicación n. 920 (s), p. 6 . Cfr.: http://www. wipo.int/freepublications/es/tk/920/wipo_pub_920.pdf

8. Ibíd., p. 5. Cfr.: http://www.wipo.int/freepublications/es/tk/920/wipo_pub_920.pdf 


\section{Protección internacional}

A lo largo de los trabajos del Comité Intergubernamental sobe Recursos Genéticos, Conocimientos Tradicionales y Folclore de la ompi se ha visto un importante avance en la necesidad de proteger estos recursos ante la tendencia a la apropiación y el uso indebido por parte de de terceros. El vigente sistema de propiedad intelectual presenta limitantes en cuanto a los sujetos, el objeto, la duración y las excepciones y limitaciones de dicha protección, entre otros elementos. Las disposiciones de derecho de autor parten de definir al autor como la persona física que crea una obra, y a la obra como la expresión creativa original. Aspectos que evidentemente resultan restrictivos al momento de incluir las obras de las expresiones culturales tradicionales provenientes de comunidades y que han sido transmitidas de generación en generación.

Algunos tratados internacionales promueven y protegen a los intérpretes o ejecutantes de las expresiones del folclore; tal es el caso del Convenio de Berna para la Protección de las Obras Literarias y Artísticas (1886), el Tratado de la OMPI sobre Interpretación o Ejecución y Fonogramas de 1996, y el Tratado de Beijing sobre Interpretaciones y Ejecuciones Audiovisuales (2012). Sin embargo, no existe a nivel internacional una regulación que comprenda la protección y promoción de las obras de las expresiones culturales tradiciones.

A su vez, las leyes relativas a la protección de la información confidencial (secretos comerciales) y la competencia desleal no han sido suficientes para garantizar los derechos que sobre los conocimientos tradicionales y las expresiones culturales tradicionales tienen los pueblos indígenas. De ahí que las esperanzas estén puestas en los acuerdos que se logren en el Comité Intergubernamental sobre Recursos Genéticos, Conocimientos Tradicionales y Folclore de la OMPI.

A nivel de Estados, han transcurrido varias décadas desde los primeros visos de protección de las expresiones de las culturas populares. En Latinoamérica encontramos que tanto Bolivia como Chile realizaron importantes esfuerzos por regular la utilización del folclore dentro de las leyes de derecho de autor. En el caso boliviano la protección se centró en el folclore musical. Otros ejemplos de países que han legislado en la protección del folclore son: Túnez (1967), Marruecos (1970), Argelia (1973), Senegal (1973), Kenia (1975), Mali (1977), Burundi (1978), Costa de Marfil (1978) y Guinea (1980).

A nivel regional, la Organización Africana para la Protección de la Propiedad Intelectual (OAPI) adoptó una convención en la cual reconoce la obra del folclore como obra comunitaria que difiere de la obra autoral convencional, de concepción individualista. Sin embargo, dicha convención no ha sido suficiente para hacer frente a la indebida apropiación de las obras del folclore a nivel mundial.

Tanto los textos nacionales como la referida convención regional reconocen las obras de las expresiones culturales tradicionales como parte del patrimonio 
cultural de la nación bajo nociones diferentes, pero con el elemento común de considerarlas provenientes de autores nacionales desconocidos. Cuestión esta que se vio reflejada en la revisión del Convenio de Berna de Estocolmo (1967) y París (1971) mediante el artículo 15.4, sobre la protección de las obras de autores desconocidos, que incluye las de folclore. Sin embargo, tal disposición tampoco fue suficiente para proteger dichas obras.

A nivel mundial, no es sino en 1977 cuando, a iniciativa de Bolivia, se plantea analizar la conveniencia de proteger las obras de las expresiones culturales tradicionales a través de una normativa particular universalizadora, lo anterior en el foro de la Organización de las Naciones Unidas para la Educación, la Ciencia y la Cultura (UnesCo). La iniciativa ve sus frutos en el año de 1982 con el establecimiento de las primeras "Disposiciones Tipo para Leyes Nacionales sobre la Protección del Folclore contra la Explotación Ilícita y otras Acciones Lesivas", que va a influenciar las reformas legislativas en materia de derecho de autor con una referencia específica a las expresiones culturales. Tal es el caso de México, entre otros países de la región.

A pesar de las dificultades para alcanzar un consenso sobre el concepto de "expresiones del folclore", en tales disposiciones tipo se adoptó una noción de uso exclusivo para dicho texto, en el sentido de considerarlas como aquellas "producciones integradas por elementos característicos del patrimonio artístico tradicional desarrollado y perpetuado por una comunidad o por individuos que reflejen las expectativas artísticas tradicionales de una comunidad". Esto significó un gran avance hacia una concepción comunitaria en el sistema de protección.

En 1989 la Conferencia de la unEsCo en París dictó unas recomendaciones para sus Estados miembros sobre la "Salvaguardia de la Cultura Tradicional y el Folclore”. Es así como aparece por primera vez un concepto más generalizado sobre la cultura tradicional y popular, señalando que

... es el conjunto de creaciones que emanan de una comunidad cultural fundadas en la tradición, expresadas por un grupo o por individuos y que reconocidamente responden a las expectativas de la comunidad en cuanto expresión de su identidad cultural y social; las normas y los valores se transmiten oralmente, por imitación o de otras maneras. Sus formas comprenden, entre otras, la lengua, la literatura, la música, la danza, los juegos, la mitología, los ritos, las costumbres, la artesanía, la arquitectura y otras artes.

Esta nueva definición profundiza aquella establecida en el Glosario de términos de la ompi del año 1980, en la que la voz 119 decía: "Desde la perspectiva de la protección jurídica, se entiende que folklore son las obras pertenecientes a la herencia cultural de una nación, creadas, conservadas y elaboradas en comunidades autóctonas de generación en generación por personas no identificadas". Por lo 
que se entendían como elementos de la definición: a) las formas en que se manifiesta la cultura tradicional, b) que hagan parte de la identidad y del patrimonio de una comunidad tradicional o indígena y c) que se transmitan de generación en generación. Ejemplos de esta clase de obras son: danzas, canciones, artesanías, diseños, ceremonias, cuentos.

Hoy en día, un número cada vez mayor de países ha regulado sobre la materia a la luz de las leyes de derecho de autor: Túnez (1967 y 1994); Bolivia (1968 y 1992); Chile, Marruecos e Irán (1970); Argelia y Senegal (1973); Kenia (1975 y 1989); Mali y Cuba (1977); Burundi y Costa de Marfil (1978); Sri Lanka (1979); Guinea (1980); Barbados, Camerún, Colombia, Congo y Madagascar (1982); Ruanda (1983); Benín y Burkina Faso (1984); República Centroafricana y Gana (1985); República Dominicana y Zaire (1986); Indonesia (1987); Nigeria (1988 y 1992); Lesoto y Malawi (1989); Angola (1990); Togo (1991); Níger (1993); Panamá (1994).

Desde la segunda mitad del siglo xx, la Organización de las Naciones Unidas y sus agencias especializadas han venido trabajando en la reivindicación de los derechos de los pueblos indígenas, y en consecuencia en la protección de su saber tradicional y de su identidad. Estos trabajos han empezado a mostrar sus resultados en el establecimiento de diversos instrumentos normativos universales, negociados y ratificados todos por México, con los cuales el país ha ido asumiendo nuevos compromisos de carácter vinculante, a saber: el Convenio 169 de la Organización Internacional del Trabajo sobre Pueblos Indígenas y Tribales en Países Independientes (C169), ratificado el 5 de septiembre de 1990; el Convenio sobre la Biodiversidad Biológica (СDB), ratificado el 11 de marzo de 1993; la Declaración Universal de la UNEsco sobre Diversidad Cultural, aprobada el 12 de noviembre de 2001; el Convenio para la Salvaguardia del Patrimonio Cultural Inmaterial (CSPCI), ratificado el 14 de diciembre de 2005; el Convenio sobre la Promoción y Protección de la Diversidad de las Expresiones Culturales (CDEC), aprobado el 20 de octubre de 2005 y ratificado el 7 de julio de 2006, y la Declaración de las Naciones Unidad sobre los Derechos de los Pueblos Indígenas, aprobada el 13 septiembre de 2007.

Un estudio más amplio y armonizado de las disposiciones internacionales vigentes para México nos conduce también a incluir en el mapa objeto de estudio el análisis de la propiedad intelectual a la luz de los derechos humanos. Estos instrumentos internacionales son: la Declaración Universal de los Derechos Humanos, la Declaración Americana de los Derechos y Deberes del Hombre, la Convención Americana sobre los Derechos Humanos (CADH), publicada en el Dof el 7 de mayo de 1981, y su Protocolo Adicional en materia de Derechos Económicos, Sociales y Culturales (Protocolo de San Salvador), publicado en el Dof el 1 de septiembre de 1998, así como el Pacto Internacional de Derechos Económicos, Sociales y Culturales, publicado en el Dof el 12 de mayo de 1981. 
Todos son claros ejemplos del reconocimiento internacional de la propiedad intelectual como un derecho humano.

La mundialización de las economías, la sociedad del conocimiento, el avance acelerado en las tecnologías de la información y el cambio de paradigmas en la política internacional de las Naciones Unidas, entre otros, explican los acuerdos alcanzados en las últimas décadas para promover y proteger la diversidad, tanto biológica como cultural, de estos nuevos fenómenos homogeneizadores a fin de garantizar el respeto de la integridad del ser humano y de los pueblos indígenas.

Los ejemplos de protección a nivel nacional, aunados a los avances en las negociaciones de los tratados internacionales de los últimos años, enmarcan y justifican los trabajos de negociación en el seno de la OMPI.

Con el propósito de presentar brevemente el mapa normativo que rige para México en materia de protección de las expresiones culturales de los pueblos indígenas, haremos a continuación una breve reseña de los principales tratados internacionales vigentes. Dichos tratados deben ser analizados e interpretación de manera armónica entre sí, y de manera prevalente con respecto a las leyes nacionales.

\section{i. Convenio i69 (Ci69) de la Organización Internacional de Trabajo (oit)sobre Pueblos Indígenas y Tribales en Países INDEPENDIENTES}

Este Convenio se aplica a los pueblos tribales en países independientes, cuyas condiciones sociales, culturales y económicas les distinguen de otros sectores de la colectividad nacional y de los pueblos en países independientes considerados indígenas.

Los principios fundamentales para la promoción y protección de los pueblos indígenas radican en: a) la no discriminación de sus derechos con miras a garantizarles los desafíos causados por la desigualdad, b) el reconocimiento como garantes de la diversidad cultural, activo esencial para su desarrollo, y c) la participación y consulta de los pueblos indígenas. Así pues, el C169 propone medidas especiales para combatir la vulnerabilidad e impone la participación de los pueblos indígenas en el respeto de su cultura y sus derechos.

Los gobiernos deberán asumir la responsabilidad de desarrollar, con la participación de los pueblos interesados, una acción coordinada y sistemática con miras a proteger los derechos de esos pueblos y a garantizar el respeto de su integridad.

$\mathrm{Al}$ aplicar las disposiciones del convenio, los Estados deberán reconocer y proteger los valores y prácticas sociales, culturales, religiosas y espirituales de tales pueblos. Además, se deberán efectuar estudios, en cooperación con ellos, a fin de evaluar su incidencia social, espiritual y cultural. Asimismo, se deberán estable- 
cer mecanismos de protección contra la violación de sus derechos y programas de formación profesional, por lo menos iguales a los de los demás ciudadanos.

En dicho Convenio se reconocen las artesanías, las industrias rurales y comunitarias y las actividades tradicionales como factores importantes del mantenimiento de su cultura y de su autosuficiencia y desarrollo económicos. Por último, corresponde a los gobiernos facilitar los contactos y la cooperación entre los pueblos.

\section{Convenio sobre la Diversidad Biológica (CDb) de la Secretaría de Diversidad Biológica}

En 1998, el Programa de las Naciones Unidas para el Medio Ambiente (PNuma) estableció un grupo de trabajo para la elaboración de un texto jurídico para la conservación y uso sostenible de la diversidad biológica. En mayo de 1992 se aprobó finalmente el Convenio sobre la Diversidad Biológica (CDB), que entró en vigor el 29 de diciembre de 1993, al ser ratificado por 30 países ${ }^{9}$. El CDB reconoce, entre otras cosas, el derecho soberano de los Estados sobre sus recursos biológicos, así como la cercana dependencia con el conocimiento tradicional de pueblos y comunidades indígenas que implican estilos de vida basados en estas riquezas. Así mismo, establece la pertinencia de compartir los beneficios de manera equitativa por el uso y la explotación del conocimiento tradicional y las innovaciones y prácticas relevantes que se han desarrollado para la conservación y el mejoramiento de muchas especies naturales, así como el uso sustentable de sus componentes ${ }^{10}$. El CDB abre una puerta para la protección adecuada, entre otras cosas, de los conocimientos tradicionales de las comunidades indígenas, pues establece: "Formas y mecanismos de protección a estos grupos y a sus creaciones, sobre todo la manera en que los beneficios serán repartidos justa y equitativamente sin perder su fin principal que es la conservación y uso adecuado de la biodiversidad"11.

Según lo establecido por los artículos 3 y 15.1, se reservó a los Estados el derecho de explotar sus propios recursos, contraviniendo la tendencia y falsa creencia anterior de que todo era patrimonio de la humanidad ${ }^{12}$.

9. Convenio sobre la Diversidad Biológica, Historia del Convenio. Cfr.: http://www. cbd.int/history/

10. Cfr. Sadahi, Suman, et al., Biopiracy Imitations not Innovations, trad. propia, Nueva Delhi, Gene Campaign, 2007, p.15.

11. Castillo Pérez, Leyda Sughei, Régimen jurídico para la protección de la medicina tradicional y otros usos de la biodiversidad en las comunidades indigenas, México, Porrúa, 2006, p. 25.

12. Cfr. Naciones Unidas, Convenio de la Diversidad Biológica, 1992. Cfr.: http://www. cbd.int/doc/legal/cbd-es.pdf 
Como señala expresamente el convenio, sus tres principales objetivos son: 1) la conservación de la diversidad biológica, 2) la utilización sostenible de sus componentes y 3) la participación justa y equitativa en los beneficios que se deriven de la utilización de recursos genéticos ${ }^{13}$. Es por ello que dentro del marco del Convenio se buscó crear un acuerdo que apoyara y desarrollara el tercero de estos objetivos. Así, el 29 de octubre de 2010, en Nagoya (Japón), se adoptó el Protocolo de Nagoya sobre Acceso a los Recursos Genéticos y Participación Justa y Equitativa en los Beneficios que se Deriven de su Utilización.

\section{Protocolo de Nagoya, ratificado el i6 de mayo de 2012}

El 29 de octubre de 2010 se adoptó el Protocolo de Nagoya sobre Acceso a los Recursos Genéticos y Participación Justa y Equitativa en los Beneficios que se Deriven de su Utilización, en el marco del CDB. En él se establecen las condiciones de cooperación mutuamente acordadas entre las partes contratantes y se promueve el uso de recursos genéticos de los conocimientos tradicionales, al fortalecer la oportunidad de compartir de manera justa y equitativa los beneficios que permitan que las comunidades puedan beneficiarse del uso de sus conocimientos, innovaciones y prácticas ${ }^{14}$. En este sentido, el Protocolo establece las condiciones sobre participación en los beneficios, incluso en relación con los derechos de propiedad intelectual.

Cabe destacar que hasta el día de hoy el Protocolo no ha entrado en vigor. México lo ratificó el 16 de mayo de 2012.

En cuanto al acceso a la tecnología y su transferencia, el Protocolo establece que la tecnología, sujeta a patentes y otros derechos de propiedad intelectual, deberá hacerse en condiciones que tengan en cuenta la protección adecuada y eficaz de los derechos de propiedad intelectual y sean compatibles con ella. Así mismo, se deberá asegurar el intercambio de los resultados de las investigaciones técnicas, científicas y socioeconómicas, así como de la información sobre programas de capacitación y de estudio, conocimientos especializados, conocimientos autóctonos y tradicionales. Al fomentarse esa cooperación deberá prestarse especial atención al desarrollo y fortalecimiento de la capacidad nacional, mediante el desarrollo de los recursos humanos y la creación de instituciones.

Por otro lado, los Estados fomentarán y desarrollarán métodos de cooperación para el desarrollo y la utilización de tecnologías, incluidas las autóctonas y tradicionales, entre las que hace mención particular a las que tengan valor medicinal o agrícola o valor económico de otra índole, o que tengan importancia social, científica o cultural.

13. Cfr. Naciones Unidas, op. cit., nota 239.

14. Protocolo de Nagoya. 
Si bien el CDB y su Protocolo hacen referencia tangencial a la cuestión de las expresiones culturales tradicionales, sus principios se verán reflejados en la Declaración y el Convenio sobre Diversidad Cultural. Estudios recientes demuestran la estrecha vinculación que existe entre la diversidad cultural y la biológica.

\section{Declaración Universal de la unesco sobre Diversidad}

Cultural, aprobada el i2 de noviembre de 200 I

Mediante esta declaración universal se reafirma la plena realización de los derechos humanos y de las libertades, al igual que la noción de cultura como "el conjunto de los rasgos distintivos espirituales y materiales, intelectuales y afectivos que caracterizan a una sociedad o a un grupo social y que abarca, además de las artes y las letras, los modos de vida, las maneras de vivir juntos, los sistemas de valores, las tradiciones y las creencias".

Es la cultura la que garantiza la identidad, la cohesión social y el desarrollo de una economía fundada en el saber, cuestiones propias del debate contemporáneo.

Los principios reguladores de esta declaración son: la diversidad cultural como patrimonio común de la humanidad, el pluralismo cultural y la diversidad cultural como factor de desarrollo.

En este sentido, se considera la cultura como fuente de intercambios, de innovación y de creatividad. La diversidad cultural se reconoce necesaria para el género humano como la diversidad biológica para los organismos vivos. Se pide a los Estados que adopten políticas que conserven la diversidad cultural, lo cual se define como pluralismo cultural. La cuestión es inseparable de un contexto democrático pues propicia los intercambios culturales y el desarrollo de las capacidades creadoras que alimentan la vida pública. La diversidad cultural amplía las posibilidades de elección que se brindan a todos. A su vez, la diversidad cultural estimula el crecimiento económico y es el medio de acceso a una existencia intelectual, afectiva, moral y espiritual satisfactoria.

De otra parte, los Estados asumen el compromiso de respetar los derechos humanos y las libertades fundamentales, en particular los derechos de las personas que pertenecen a minorías y los de los pueblos indígenas. No se puede invocar la diversidad cultural para vulnerar los derechos humanos garantizados por el derecho internacional, ni para limitar su alcance.

Con plena claridad se establece que los derechos culturales son parte integrante de los derechos humanos, que son universales, indisociables e interdependientes. El desarrollo de una diversidad creativa exige la plena realización de los derechos culturales, tal como los definen los artículos 27 de la Declaración Universal de Derechos Humanos y 13 y 15 del Pacto Internacional de Derechos Económicos, Sociales y Culturales. Toda persona debe tener la posibilidad de expresarse, crear y difundir sus obras en la lengua que desee, y en particular en su lengua mater- 
na; toda persona tiene derecho a una educación y una formación de calidad que respeten plenamente su identidad cultural; toda persona debe tener la posibilidad de participar en la vida cultural que elija, y de conformarse con las prácticas de su propia cultura, dentro de los límites que impone el respeto de los derechos humanos y de las libertades fundamentales.

Todas las culturas tienen el derecho a expresarse y darse a conocer libremente, así como al respeto de sus expresiones culturales. Son garantes de la diversidad cultural: la libertad de expresión, el pluralismo de los medios de comunicación, el plurilingüismo, la igualdad de acceso a las expresiones artísticas, al saber científico y tecnológico -comprendida su presentación en forma electrónica- y la posibilidad, para todas las culturas, de estar presentes en los medios de expresión y de difusión.

Por otro lado, se considera el patrimonio cultural como una fuente importante de la creatividad al inspirar el diálogo entre las culturas. Ante los cambios económicos y tecnológicos actuales se debe prestar particular atención a la diversidad de la oferta creativa, al justo reconocimiento de los derechos de los autores y de los artistas, así como al carácter específico de los bienes y servicios culturales que, por ser portadores de identidad, de valores y sentido, no deben ser considerados mercancías o bienes de consumo como los demás.

La Declaración hace un llamado a cada Estado a respetar las obligaciones internacionales asumidas y a definir su política cultural y aplicarla utilizando para ello los medios de acción que juzgue más adecuados, ya se trate de modalidades prácticas de apoyo o de marcos reglamentarios apropiados. A su vez, se apela a la solidaridad internacional y a forjar relaciones de colaboración entre el sector público, el sector privado y la sociedad civil.

Esta Declaración constituye un gran avance en la protección y promoción de diversidad cultural, de la cual México se beneficia.

\section{Convención para la Salvaguardia del Patrimonio Cultural INMATERIAL, DOF 28 DE MARZO DE 2006}

La Convención en cita parte de definir el patrimonio cultural inmaterial como "los usos, representaciones, expresiones, conocimientos y técnicas -junto con los instrumentos, objetos, artefactos y espacios culturales que les son inherentesque las comunidades, los grupos y en algunos casos los individuos reconozcan como parte integrante de su patrimonio cultural". Quedan comprendidos en este concepto manifestaciones en el marco de tradiciones y expresiones orales, artes del espectáculo, usos sociales, rituales y actos festivos, conocimientos y usos relacionados con la naturaleza y el universo, y técnicas artesanales tradicionales.

Los Estados asumen el compromiso de definir los distintos elementos del patrimonio cultural inmaterial presentes en su territorio, con la participación de las 
comunidades, los grupos y las organizaciones no gubernamentales pertinentes, y de tomar medidas de salvaguardia encaminadas a: a) adoptar una política general en cuanto a la función del patrimonio cultural inmaterial en la sociedad, b) designar o crear uno o varios organismos competentes para la salvaguardia del patrimonio cultural inmaterial, c) fomentar estudios científicos, técnicos y artísticos, así como metodologías de investigación, para la salvaguardia eficaz del patrimonio cultural inmaterial, y d) adoptar las medidas de orden jurídico, técnico, administrativo y financiero. Para lo anterior, la educación, la reglamentación y el fortalecimiento de capacidades nacionales resultan fundamentales.

La finalidad es salvaguardar y hacer respetar el patrimonio común inmaterial con la debida cooperación internacional. En el plano nacional, se podrán establecer inventarios y otras medidas, entre ellas de educación, siempre con la participación de las comunidades indígenas. En el plano internacional, se trabajará para crear listas representativas, programas y proyectos, siempre respetando los fines del Convenio.

En este contexto, la OMPI y la UNESCo han establecido recientemente programas de cooperación con las comunidades tradicionales.

\section{Convenio sobre la Promoción y Protección de la Diversidad de las Expresiones Culturales (CDec), ratificado por México EN JULIO DE 2006}

Este Convenio surge con el propósito de promover la protección y promoción de la diversidad de las expresiones culturales, fomentar la interculturalidad y promover el respeto de la diversidad de las expresiones culturales.

El Convenio se fundamenta en los siguientes principios rectores: a) respeto de los derechos humanos y las libertades fundamentales, b) soberanía nacional, c) igualdad, dignidad y respeto de todas las culturas, d) solidaridad y cooperación internacional, e) complementariedad de los aspectos económicos y culturales del desarrollo, f) desarrollo sostenible, g) acceso equitativo y h) apertura y equilibrio.

Por su parte, el Convenio enriquece el glosario internacional mediante la definición de las siguientes cuestiones: diversidad cultural, contenido cultural, expresiones culturales, actividades, bienes y servicios culturales, industrias culturales, políticas y medidas culturales, e interculturalidad.

A su vez, establece el derecho soberano de los Estados a formular y aplicar sus políticas culturales y adoptar medidas para proteger y promover la diversidad de las expresiones de cultura. Para lo anterior, los Estados podrán crear, producir, difundir y distribuir sus propias expresiones culturales, establecer políticas para la educación y sensibilización del público y la integración de la cultura en el desarrollo sostenible. 


\section{Declaración de las Naciones Unidad sobre los Derechos de los Pueblos Indígenas, Aprobada El I3 De Septiembre de 2007}

Mediante esta Declaración de la onu, negociada con la activa y constructiva participación de México, se reconoce a los pueblos indígenas el derecho a la libre determinación y a perseguir libremente su desarrollo económico, social y cultural. Así mismo, se les faculta a conservar y reforzar sus propias instituciones políticas, jurídicas, económicas, sociales y culturales.

La Declaración reconoce a los pueblos indígenas el derecho a practicar y revitalizar sus tradiciones y costumbres culturales y a manifestar, practicar, desarrollar y enseñar sus tradiciones, costumbres y ceremonias espirituales y religiosas. De tal forma, es un derecho inherente a los pueblos indígenas revitalizar, utilizar, fomentar y transmitir a las generaciones futuras sus historias, idiomas, tradiciones orales, filosofías, sistemas de escritura y literatura. Para ello, tienen derecho a mantener, controlar, proteger y desarrollar la propiedad intelectual de dicho patrimonio cultural, sus conocimientos tradicionales y sus expresiones culturales tradicionales.

A su vez, se les faculta a impartir la educación en sus propios idiomas, en consonancia con sus métodos culturales de enseñanza y aprendizaje. La dignidad y diversidad de sus culturas, tradiciones, historias y aspiraciones deben quedar debidamente reflejadas en la educación y la información pública. Así pues, deberán participar en la adopción de decisiones en las cuestiones que afecten sus derechos y cooperar de buena fe a fin de obtener su consentimiento libre, previo e informado.

Los pueblos indígenas desposeídos de sus medios de subsistencia y desarrollo tienen derecho a una reparación justa y equitativa mediante un proceso independiente, imparcial, abierto y transparente, en el que se reconozcan debidamente las leyes, tradiciones y costumbres. La reparación se hará por medios que pueden incluir la restitución o, cuando ello no sea posible, una indemnización justa y equitativa por las tierras, los territorios y los recursos que tradicionalmente les pertenecen.

De conformidad con la Declaración, los pueblos indígenas tienen derecho a sus propias medicinas tradicionales y a mantener sus prácticas de salud, incluida la conservación de sus plantas medicinales, animales y minerales de interés vital.

En definitiva, mediante esta Declaración los pueblos indígenas logran un gran avance en la libre determinación de su patrimonio cultural, sus conocimientos y sus expresiones culturales tradicionales y las manifestaciones de sus ciencias, tecnologías y cultura. 


\section{Protección NaCional}

\section{Reforma constitucional EN MATERIA indígena}

La tendencia de las políticas mexicanas ha ido también evolucionando, respondiendo paulatinamente a la necesidad de reconocer los derechos de las minorías étnicas y la diversidad cultural. Este reconocimiento se verá reflejado en beneficio de la colectividad pues, a decir de Jasso Martínez, es "la valoración del patrimonio histórico que nos legaron los pueblos mesoamericanos y que continúa vigente" 15 . Como parte de este cambio para dar cabida a la diversidad y respondiendo a la urgencia nacional de revalorar la riqueza cultural indígena, en el año 2001 se presentaron reformas constitucionales sustanciales a los artículos $1 .^{\circ}, 2 .^{\circ}, 4 .^{\circ}, 18$ y 115, marcando la pauta para una protección eficiente de los derechos indígenas, en lo general, y de la protección de las expresiones culturales tradicionales, en lo particular. En tales artículos se garantiza el derecho de los pueblos y las comunidades indígenas a la autonomía para preservar y enriquecer sus lenguas, conocimientos y todos los elementos que constituyan su cultura e identidad, así como la obligación para el Estado mexicano de definir y desarrollar programas educativos de contenido regional que reconozcan la herencia cultural de sus pueblos y el debido aprovechamiento de la medicina tradicional ${ }^{16}$.

Posterior a la reforma de 2001, también tuvieron lugar reformas trascendentales en materia de derechos humanos que impactan de manera sustancial los derechos consagrados a los pueblos y comunidades indígenas. Estas modificaciones, iniciadas formalmente en 2009, fueron promulgadas el 9 de junio de 2011. Mediante ellas se enmiendan 11 artículos de la Constitución Política de los Estados Unidos Mexicanos (1, 13, 11, 15, 18, 29, 33, 89, 97,102 y 105).

$\mathrm{Su}$ impacto en los derechos indígenas radica primordialmente en lo relativo a la nueva obligación que impone al Estado mexicano de "promover, respetar, proteger y garantizar los derechos humanos de conformidad con los principios de universalidad, interdependencia, indivisibilidad y progresividad"17.

Máxime porque, como señala atinadamente CARBoneLL ${ }^{18}$, la exigencia es aplicable a todas las autoridades mexicanas en todos los ámbitos y niveles de gobierno sin distinción alguna, pues no se debe distinguir donde la Constitu-

15. Jasso Martínez e Ivy Jacaranda. Reconocimiento de los derechos indígenas. ¿Reformulación del Estado mexicano? Desacatos, enero-abril, 2013. Cfr.: http://www.redalyc. org/articulo.oa?id=13925607003 Fecha de consulta: 10 de abril de 2014.

16. Artículo 2. ${ }^{\circ}$ Constitución Política de los Estados Unidos Mexicanos.

17. Ibíd.

18. Cfr. Carbonell, Miguel, Las obligaciones del Estado en el artículo 1 de la Constitución mexicana, México, Instituto de Investigaciones Jurídicas - UnAm, 2011, p. 67. Cfr.: http://biblio.juridicas.unam.mx/libros/7/3033/5.pdf 
ción no lo hace. Esta reforma constitucional atiende el compromiso del Estado mexicano por salvaguardar íntegramente los derechos del ser humano contemplados en aproximadamente 150 tratados internacionales y protocolos referidos a los derechos humanos ${ }^{19}$, incluyendo el Convenio 169 de la oit relativo a los derechos de los indígenas que ya se ha comentado y los demás tratados aquí ya mencionados. Es por ello, reflexiona CARbonell, que el Estado mexicano debe respetar y proteger los tratados internacionales que contemplen derechos fundamentales en favor de los pueblos y comunidades indígenas, obligación que implica no solo destinar recursos económicos para satisfacer esas potestades, sino adoptar medidas encaminadas a evitar su violación y mecanismos defensivos por si existe transgresión ${ }^{20}$.

"Hay que enfatizar el hecho de que la legislación nacional no sólo debe ser no contradictoria con los instrumentos jurídicos internacionales, sino que debe contener las disposiciones necesarias para hacer de éstos, normas completamente aplicables por las autoridades locales" 21 .

Destaca por su importancia el fortalecimiento del Estado de derecho, al elevar a los tratados internacionales de derechos humanos al rango constitucional, con base en la premisa de que "los derechos humanos encarnan valores que son comunes a todos los mexicanos, y, por ende, eleva su protección y promoción en el sistema internacional de una política de Estado que, como tal, responde al interés nacional por encima de las diferencias programáticas de los gobiernos en turno"22.

Queda en manos de las autoridades nacionales el desarrollo de dichos tratados y la aplicación armónica de las leyes nacionales a dichos tratados.

\section{Leyes APLICABLES}

Dentro del sistema jurídico nacional son diversas las disposiciones que existen para reconocer y proteger las expresiones culturales tradicionales. Algunas se encuentran dentro del sistema jurídico de propiedad intelectual, pero hay otras que se han ido diseñando y adaptando a las necesidades de los pueblos y comunidades indígenas del país.

19. Cfr. ibíd., p. 70.

20. Cfr. ibíd., p. 75.

21. Ibíd., p. 77.

22. Saltalamacchia Ziccardi, Natalia y Covarrubias Velasco, Ana, La dimensión internacional de la Reforma de Derechos Humanos: Antecedentes Históricos, México, Instituto de Investigaciones Jurídicas - UNAM, 2011, p. 2. Cfr.: http://biblio.juridicas.unam. $\mathrm{mx} / \mathrm{libros} / 7 / 3033 / 3 . \mathrm{pdf}$ 


\section{a. Ley Federal del Derecho de Autor}

En el marco de los derechos autorales, la protección del folclore toma fuerza mediante el capítulo correspondiente a las culturas populares, otorgando una protección a las obras artísticas, literarias, artesanales y, en general, a todas las manifestaciones derivadas de los usos y costumbres de la sociedad pluricultural de México, pero haciendo énfasis en que no cuentan con un autor identificado ${ }^{23}$, pues en caso contrario la protección sería automática bajo el esquema tradicional de obra protegida por el derecho de autor.

No obstante, cabe destacar que la protección que la legislación autoral brinda a las obras derivadas del folclore solo las tutela contra su deformación, siempre y cuando sea hecha con el objeto de causar un demérito a la obra o dañar la reputación de la comunidad a la que pertenecen ${ }^{24}$. En consecuencia, se trata de una protección limitada a los derechos morales donde el Estado mexicano asume la defensa de la integridad de las obras autóctonas al carecer de un autor único y bien definido que pueda hacer valer el derecho por sí mismo.

Por otro lado, a la luz de la legislación autoral vigente, el uso de las obras de arte popular es libre, permitiéndose su fijación, representación, publicación, comunicación o utilización en cualquiera de sus formas, siempre y cuando se mencione la comunidad o etnia a la que pertenecen, salvaguardando así los derechos morales de paternidad e integridad consagrados en la misma ley ${ }^{25}$. Cabe destacar el papel de defensa que la misma legislación da al Instituto Nacional del Derecho de Autor ${ }^{26}$ al otorgarle el derecho y la obligación de vigilar el cumplimiento de estas disposiciones que protegen los derechos morales de las culturas populares en nuestro país ${ }^{27}$.

Vale aquí cuestionarnos si dicha disposición es coherente con los convenios internacionales en los que se establece la libre determinación y el consentimiento libre informado y previo de los pueblos indígenas, o si, por el contrario, se trata de una autorización legal que simplemente facilita su debida utilización pero que en cuanto a los derechos económicos derivados de su uso implica un estudio armonizado con los derechos fundamentales consagrados en la Constitución Política y en los tratados internacionales, sobre todo en cuanto a la repartición

23. Ley Federal del Derecho de Autor, art. 157. Cfr.: http://www.diputados.gob.mx/ LeyesBiblio/pdf/122.pdf

24. Ibíd., art. 158.

25. Ibíd., arts. 159 y 160.

26. El Instituto Nacional del Derecho de Autor (INDAUtor) es la oficina nacional encargada de los asuntos relacionados con los derechos autorales y conexos en México. Cfr.: http://www.indautor.gob.mx/?navegador $2=\% 271 \% 27 \&$ valor $=$

27. Ibíd., art. 161. 
justa y equitativa de beneficios a favor de las comunidades indígenas poseedoras del saber o expresión cultural tradicional.

A su vez, la Ley Federal del Derecho de Autor, en el apartado referente a los derechos conexos, Título $\mathrm{v}$, protege las interpretaciones de las obras del folclore (art. 116 LFDA) sin hacer mención específica de las cuestiones aquí referidas.

\section{b. Ley de Propiedad Industrial}

Por su parte, establece la misma Ley Federal del Derecho de Autor en sus artículos 231, numeral Ix, y 232 que corresponde al Instituto Mexicano de Propiedad Industrial (IMPI) velar por la sanción de las infracciones en materia de comercio cuando las obras populares, sean estas literarias o artísticas, de arte popular o artesanal, se utilicen con fines de lucro (directo o indirecto) en contravención de lo dispuesto en el artículo 158 de dicha ley. Para ello se faculta al ImPI para imponer multas al infractor. El referido artículo 158 establece: "Las obras literarias, artísticas, de arte popular o artesanal, desarrolladas y perpetuadas en una comunidad o etnia originaria o arraigada en la República Mexicana, estarán protegidas por la presente Ley contra su deformación, hecha con objeto de causar demérito a la misma o perjuicio a la reputación o imagen de la comunidad o etnia a la cual pertenecen". En virtud del presente artículo se le confiere competencia al IMPI para sancionar las infracciones por las deformaciones que se causen a las obras de arte popular o artesanal con fines de lucro directo o indirecto. Esta disposición resulta también insuficiente para garantizar el desarrollo con cultura e identidad de las comunidades indígenas.

Cabe mencionar que también son aplicables para la protección de las obras del folclore otras figuras propias de la propiedad intelectual, tales como las marcas, las de arte o dibujo aplicado, la de competencia desleal y secreto industrial, entre otras.

\section{c. Ley Federal sobre Monumentos y Zonas Arqueológicos, Artísticos e Históricos}

La preservación del patrimonio cultural material mexicano es una forma de lograr una identidad nacional basada en la interculturalidad de la sociedad mexicana, de la cual ya se habló; es por ello que, como parte de la legislación vigente, se encuentra la Ley Federal sobre Monumentos y Zonas Arqueológicos, Artísticos e Históricos, que declara como utilidad pública la "investigación, protección, conservación, restauración y recuperación de los monumentos arqueológicos, artísticos e históricos y de las zonas de monumentos" 28 . 
Con esta legislación se pretende la salvaguarda de la riqueza histórico cultural mexicana, declarando que son propiedad de la Nación todos los bienes muebles e inmuebles producto de las culturas anteriores a la conquista española, impidiendo con ello su enajenación e incluso su reproducción sin la autorización correspondiente, estableciendo sanciones para quien intente lucrar indebidamente con el patrimonio nacional.

\section{Organismos gubernamentales}

\section{a. Comisión Nacional para el Desarrollo de los Pueblos Indigenas}

La Comisión Nacional para el Desarrollo de los Pueblos Indígenas (CDI) es un organismo descentralizado de la administración pública federal, con personalidad jurídica y patrimonio propio, autonomía operativa, técnica, presupuestal y administrativa. Una de sus misiones es la de orientar, coordinar, promover, apoyar, fomentar, dar seguimiento y evaluar los programas, proyectos, estrategias y acciones públicos para alcanzar el desarrollo integral y sustentable de las comunidades indígenas. A su vez, garantiza el ejercicio pleno de los derechos de los pueblos y comunidades indígenas, de conformidad con el artículo $2 .^{\circ}$ de la Constitución Política de los Estados Unidos Mexicanos. Así mismo, le corresponde observar el carácter multiétnico y pluricultural de la nación, reconocer el patrimonio cultural, las relaciones interculturales y la vigencia de los derechos de los pueblos y comunidades indígenas, fomentando el desarrollo sustentable para el uso racional de los recursos naturales y de las regiones indígenas, sin arriesgar el patrimonio de las generaciones futuras ${ }^{29}$. Superar los rezagos y reducir las brechas de desarrollo; proteger lugares sagrados; lograr la revalorización de las culturas y del uso de las lenguas indígenas; avanzar en la identificación de las comunidades indígenas para el ejercicio de sus derechos colectivos, y atender íntegramente a la población indígena urbana o rural, son sin duda retos de enorme trascendencia ${ }^{30}$.

Durante el periodo 2007-2012 la Comisión implementó el Programa de Desarrollo de los Pueblos Indígenas para promover su desarrollo con respeto a sus culturas, lenguas y derechos, mediante la implementación de objetivos y estrategias que permitan impulsar el desarrollo humano, favorecer la consulta y

Históricos. Diario Oficial de la Federación, 6 de mayo de 1976. Cfr.: http://www.diputados.gob.mx/LeyesBiblio/pdf/131.pdf

29. Comisión nacional para el desarrollo de los pueblos indígenas. Cfr.: http://www. cdi.gob.mx/index.php?option=com_frontpage $\&$ Itemid $=1$

30. Abreu Sierra, Xavier. Acciones de Gobierno para el desarrollo integral de los pueblos indigenas, Informe 2011, p. 7. 
participación, la armonización de los sistemas legislativos y, en general, trabajar en la revalorización de las culturas y el fomento de un diálogo intercultural ${ }^{31}$.

El desarrollo con identidad es sin duda el gran desafío de la población indígena; lograrlo implica crear un modelo que impulse el ejercicio de los derechos, genere y articule espacios amplios para la consulta y la participación indígena, focalice, oriente y dé pertinencia a la acción pública para el desarrollo humano, y favorezca la reproducción de las culturas indígenas en los diferentes ámbitos territoriales en que estas se encuentren ${ }^{32}$. Como se advierte de lo anterior, en este sentido la política pública de México realmente se ha ido extendiendo para lograr la valoración, el respeto y desarrollo de la comunidad indígena mexicana, en un marco de igualdad social.

\section{b. Comisión Nacional para el Conocimiento y Uso de la Biodiversidad}

En marzo de 1992 y en el interés de establecer un organismo para reunir información acerca de la biodiversidad mexicana y las formas de su preservación y uso sustentable es que nace la Comisión Nacional para el Conocimiento y Uso de la Biodiversidad (CONABIo), como un organismo intersecretarial ${ }^{33}$. Es una institución que genera inteligencia sobre el capital natural; sirve de puente entre la academia, el gobierno y la sociedad, y promueve que la conservación y el manejo de la biodiversidad se base en acciones realizadas por la población local, la cual debe ser un actor central en ese proceso.

\section{c. Fondo Nacional para el Fomento de las Artesanías (FONART)}

Más que de un organismo gubernamental, se trata de un fideicomiso público de la Secretaría de Desarrollo Social para promover la actividad artesanal del país y apoyar el ingreso familiar a través del comercio justo de las obras derivadas del folclore ${ }^{34}$.

\section{d. El Consejo Nacional para la Cultura y las Artes (Conaculta)}

Conaculta ha sido creado con el propósito de coordinar las políticas, los organismos y las dependencias tanto de carácter cultural como artístico del país, inclui-

31. Ibíd., p. 12.

32. Ibíd., p. 53.

33. Sarukhán Kermez, José y Seco Mata, Rosa María. Dos décadas de historia 19922012, México, Comisión Nacional para el Conocimiento y el Uso de la Biodiversidad ConABio, 2012, p. 17. Cfr.: http://www.conabio.gob.mx/web/pdf/Conabio_Dos_Decadas_de_Historia_web.pdf

34. Cfr.: http://www.fonart.gob.mx/web/ 
das las tradicionales. Para ello, estimula y promueve las expresiones de distintas regiones y grupos sociales del país para así promover, preservar y enriquecer los bienes artísticos, culturales y patrimonios históricos con que cuenta la nación.

\section{e. El Instituto Nacional de Antropología e Historia (INAH)}

Como parte de las obligaciones que el Estado mexicano ha cumplido en materia de preservación del saber tradicional y la cultura en México, en 1939 fundó el Instituto Nacional de Antropología e Historia, organismo responsable de garantizar la investigación, conservación y protección del patrimonio cultural tangible e intangible, mediante la conservación de monumentos históricos y zonas arqueológicas, así como la administración de museos, acervos documentales, fonotecas, etc., logrando con ello preservar la memoria nacional ${ }^{35}$.

\section{f. El Instituto Nacional de Bellas Artes (INBA)}

No solo preservar el saber artístico y cultural mexicano forma parte de los compromisos asumidos por México, también se ha desarrollado el apoyo para la creación de la producción artística en todas sus manifestaciones, pues, como ya se ha mencionado, el folclore es una actividad cambiante que se enriquece día tras día con el aporte de nuevas formas de expresión, ya sea en la danza, la música, la literatura, etc. Es por ello que en 1946 fue creado el Instituto Nacional de Bellas Artes, organismo del Gobierno Federal responsable de estimular la producción artística en todo el territorio nacional y promover su difusión tanto a nivel nacional como en el extranjero, logrando con ello fomentar y estimular la creación del arte mexicano. Así también, entre sus obligaciones se encuentra la de catalogar y registrar el patrimonio artístico nacional ${ }^{36}$.

\section{Conclusiones}

Las leyes de propiedad intelectual vigentes en México no contemplan de manera comprehensiva una tutela efectiva, directa y real sobre las obras de las expresiones de las culturas tradicionales. En consecuencia, se hace necesario acudir a una interpretación armónica de las distintas figuras de propiedad intelectual (derecho de autor, propiedad industrial, secretos industriales, competencia desleal, etc.), así como de los convenios internacionales suscritos y ratificados por México, que buscan la preservación de las expresiones culturales tradicionales o del folclore. 
En este sentido, se deberán interpretar las disposiciones nacionales a la luz de los tratados internacionales sobre la materia, y en caso de conflicto prevalecerán los tratados internacionales que contemplen derechos fundamentales en favor de los pueblos y comunidades indígenas.

El Estado mexicano deberá dar cumplimiento a los tratados internacionales en virtud de su carácter vinculante. Así mismo, deberá asignar recursos económicos y crear mecanismos para darles cumplimiento.

Los avances alcanzados en esta materia son reflejo de la experiencia de las comunidades indígenas y buscan hacer prevalecer la salvaguardia de la identidad y diversidad culturales y de sus valores para un desarrollo sostenible.

No hay que perder de vista que una buena protección de las obras de las expresiones culturales tradicionales permite a dichas comunidades indígenas acceder a un desarrollo económico, cultural y social que les garantice mejorar su calidad de vida. A su vez, proteger nuestra cultura tradicional es proteger nuestra identidad como nación, es estimular la creatividad, es conocernos mejor y entender nuestro pasado, es mantener nuestra diversidad biológica y cultural, es garantizar un desarrollo sostenible para México.

Con ello se demuestra que es tarea prioritaria para el Estado mexicano identificar y reconocer los derechos de los pueblos y comunidades indígenas sobre las expresiones culturales tradicionales, aun cuando no sean utilizadas comercialmente.

En la búsqueda por preservar el patrimonio cultural inmaterial o las expresiones culturales tradicionales se pretende resguardar asimismo su identificación, transmisión e incluso catalogación para asegurar su permanencia y continuidad.

Esto no quiere decir que todo esté dicho, aún pueden implementarse en nuestro país otras medidas tendientes a lograr una promoción y una protección de las obras de las expresiones culturales tradicionales, como es la creación de una legislación-marco federal sui generis que desarrolle mecanismos para promocionar y preservar la cultura y el saber tradicional en consonancia con las comunidades indígenas.

Por lo anterior es que los expertos de la Comisión Nacional para el Desarrollo de los Pueblos Indígenas sugieren los siguientes elementos para una ley de protección del saber tradicional:

- Que se reconozca el derecho de los pueblos indígenas a ser considerados como sujetos de derecho colectivo.

- Que se reconozcan los sistemas normativos propios de los pueblos indígenas aplicados por sus autoridades tradicionales.

- Que haya una retribución en especie o en dinero y el reconocimiento de que el pueblo es el creador.

- Que los pueblos indígenas participen permanentemente en la elaboración de la ley o las reformas. 
- Que se determinen claramente los mecanismos de participación y consulta de las autoridades tradicionales.

- Que se garantice el derecho a decir no y que se tengan reglas claras cuando se diga sí.

- Deben modificarse las normas de propiedad intelectual para responder a las necesidades de los pueblos ${ }^{37}$.

Por último, podemos afirmar que a nivel nacional pesa sobre las autoridades nacionales un gran trabajo de coordinación interinstitucional y de consulta con las comunidades indígenas y el sector privado para impulsar con mayor fuerza las obras del folclore. Por su parte, las comunidades indígenas tendrán que dar muestra de su capacidad de diálogo y concertación.

A nivel internacional, los trabajos de la OMPI serán decisivos en la consolidación del marco jurídico internacional sobre la promoción y protección de las expresiones culturales tradicionales.

\section{BibliografíA}

Aragón Andrade, Orlando. Indigenismo, movimientos y derechos indígenas en México. La Reforma del Artículo $4 .{ }^{\circ}$ Constitucional de 1992, México, Universidad Michoacana de San Nicolás de Hidalgo, 2007.

Carbonell, Miguel. Derechos de los pueblos y comunidades indígenas. Legislación básica, México, Porrúa, 2004.

Carbonell, Miguel (coord.). Constitución Politica de los Estados Unidos Mexicanos, comentada y concordada, México, 20. ${ }^{\text {a }}$ ed., Porrúa, Instituto de Investigaciones Jurídicas - UNAM, 2009.

Castillo Ramírez, Guillermo. Las representaciones de los grupos indígenas y el concepto de nación en Forjando patria de Manuel Gamio. Cuicuilco, enero-abril, 2013.

Comisión Nacional para el Desarrollo de los Pueblos Indígenas. Decreto por el que se aprueba el Programa para el Desarrollo de los Pueblos Indígenas 2009-2012, México, Diario Oficial de la Federación, 4 de diciembre de 2009.

Comisión Nacional para el Desarrollo de los Pueblos Indígenas. Identidad cultural y los conocimientos tradicionales en México. Características de los artesanos y las empresas de artesanías en México, Oaxaca, agosto de 2009. Disponible en: http:// www.impi.gob.mx/work/sites/IMPI/resources/LocalContent/1436/1/6.pdf

37. Comisión Nacional para el Desarrollo de los Pueblos Indígenas. Identidad cultural $y$ los conocimientos tradicionales en México. Características de los artesanos y las empresas de artesanias en México, Oaxaca, agosto de 2009. Cfr.: http://www.impi.gob.mx/work/sites/ IMPI/resources/LocalContent/1436/1/6.pdf 
Gómez Madrigal, Laura. Protección de la tradición. Los derechos no tradicionales de la propiedad intelectual. La Propiedad Inmaterial, n. ${ }^{\circ}$ 17, Universidad Externado de Colombia, 2013, p.107. Disponible en: http://revistas. uexternado.edu.co/index. php?journal=propin\&page $=$ article\&op $=v i e w \& p a$ th\% $\%$ B $\% 5 \mathrm{D}=3581$

Macionis, John y Plummer, Ken. Sociología, Madrid, Pearson, 2007.

Organización Mundial de la Propiedad Intelectual. Propiedad Intelectual y Conocimientos Tradicionales, folleto n. ${ }^{\circ}$ 2, publicación n. 920 (s), p. 5. Disponible en: http://www.wipo.int/freepublications/es/tk/920/wipo_pub_920.pdf

Organización Mundial de la Propiedad Intelectual. Revista de la OMPI, Ginebra, n. ${ }^{\circ}$ 3, junio de 2011. Disponible en: http://www.wipo.int/export/sites/www/ wipo_magazine/es/pdf/2011/wipo_pub_121_2011_03.pdf

Organización Mundial de la Propiedad Intelectual. La protección de los conocimientos tradicionales de la India. Revista de la OMPI, n. ${ }^{\circ} 3$, junio de 2011. Disponible en: http://www.wipo.int/wipo_magazine/es/2011/03/ article_0002.html

Organización Mundial de la Propiedad Intelectual. Revista de la OMPI, n. ${ }^{\circ}$ 6, Ginebra, diciembre de 2011.

Sobrevila, Claudia. The Role of Indigenous Peoples in Biodiversity Conservation. The Natural but Often Forgotten Partners, trad. propia, Washington, The World Bank, mayo de 2008.

Saltalamacchia Ziccardi, Natalia y covarrubias velasco, Ana. La dimensión internacional de la Reforma de Derechos Humanos: Antecedentes Históricos, México, Instituto de Investigaciones Jurídicas unam, 2011, p. 2. Véase: http:// biblio.juridicas.unam.mx/libros/7/3033/3.pdf

Sarukhán Kermez, José y Seco Mata, Rosa María. Dos décadas de historia 1992-2012, México, Comisión Nacional para el Conocimiento y Uso de la Biodiversidad, conabio, 2012. Disponible en: http://www.conabio.gob.mx/ web/pdf/Conabio_Dos_Decadas_de_Historia_web.pdf

\section{Convenios y tRATADos INTERNACIONALES}

Convenio de Berna para la Protección de las Obras Literarias y Artísticas.

Tratado de la OMPI sobre Interpretación o Ejecución y Fonogramas.

Tratado de Beijing sobre Interpretaciones y Ejecuciones Audiovisuales.

Convenio 169 de la Organización Internacional del Trabajo sobre Pueblos Indígenas y Tribales en Países Independientes.

Convenio sobre la Biodiversidad Biológica (CDB).

Convenio para la Salvaguardia del Patrimonio Cultural Inmaterial (CSPCI).

Convenio sobre la Promoción y Protección de la Diversidad de las Expresiones Culturales (CDEC). 
Declaración Universal de la UnEsco sobre Diversidad Cultural.

Declaración de las Naciones Unidas sobre los Derechos de los Pueblos Indígenas.

LEYES NACIONALES

Constitución Política de México.

Ley Federal del Derecho de Autor.

Disposiciones sobre Competencia Desleal.

Ley de Propiedad Industrial.

Ley Federal sobre Monumentos y Zonas Arqueológicos, Artísticos e Históricos. 